\title{
Improvising with the Great Flow of Qi: Innovative Applications of Tai Ji Quan to
}

\section{Contemporary Performer Training}

\section{Min Zhu}

Western Australian Academy of Performing Arts, Edith Cowan University, Perth, Australia.

KEYWORDS

Tai Ji Quan

Mindfulness

Qi flow

Improvisation

Movement training
A B STRACT

Tai Ji Quan (TJQ) is generally viewed as an effective means of achieving the spiritual unity of the body. This paper aims to discuss how TJQ as a mindfulness-based practice can be innovatively applied to contemporary performer training, especially in the form of improvisation. This unique way of movement training is based on the motion principle of TJQ: consciousness guiding the qi, the qi guiding the body, then the body forming the shape. Practitioners are expected to improvise whilst being aware of $q i$, and are therefore able to stimulate spontaneity in improvisation, and to achieve the moment of integration of the body and mind: doing and being.

\section{Introduction}

Tai Ji Quan (TJQ) ${ }^{1}$ is not only able to improve one's physical health but can also enhance mindfulness. TJQ is a practical bodily form that might be seen as a manifestation of $\mathrm{Tai} \mathrm{Ji}$ philosophy and Daoism. It applies the principle of Yin and Yang to the human body, emphasising the consciousness that leads the qi (vital force/internal energy) to penetrate the whole body in practice. Practitioners are expected to integrate body and mind and move with the flow of energy within the practice in order to produce significant effects with minimal effort. The essential characteristics of TJQ practice, such as sustained awareness of breathing and sensations; attending to body movement on a moment-to-moment basis; gaining insights of the ultimate nature of things; 
and developing self-knowledge and wisdom, lead to TJQ being considered a form of moving meditation or meditation in motion. As Paul Posadzki and Samantha Jacques suggest, meditation and TJQ 'can be used interchangeably in the sense of results they offer (i.e., bliss and harmony), fulfilment and life satisfaction, serenity and tranquillity, joyfulness, or freedom' (Posadzki \& Jacques, 2009, p.108).

Mindfulness, as a practice originating from the practice of Eastern meditation, has a lot in common with TJQ in terms of understanding body and mind, training methods and health benefits. Both meditation and TJQ underline the unity of body and mind. They both also stress the intentional use of breathing patterns; focus on purpose and non-judgmental thinking; and develop the skill of bringing one's attention to whatever is happening in the present moment, so as to achieve psychophysical relaxation and concentration. According to Gene M. Moyle,
TJQ can serve not only to 'impact upon increasing mindfulness levels in participants, but to provide an alternate "moving" method of mindfulness practice' (2016, p.373). Therefore, the interrelatedness between TJQ and mindfulness exercises provides a basis for the discussion in this article.

Tai Ji Quan consists of a series of relatively slow movement sequences and has gradually developed into a variety of styles in practice. The physical techniques of TJQ are characterised by 'continuity, flexibility, circling and unity' (Huang, 1984, p.167). The coordination and relaxation of joints rather than muscular tension stresses continuity in how the external form of the body can be viewed as both alert, strong and awakened, while being carefully controlled by the internal circulation of qi. The positive effect on improving mentality and the emphasis on moving with the energy flow during exercise allow TJQ to be seen as 'a joyful 
artistic performance, and practitioners' daily experience of duality between body and mind is transformed into a harmonious mental unidirectionality' (Csikszentmihalyi, 1990, p.106). It can be said that TJQ as a bodily practice has been creatively applied to performance-making and performer training by many contemporary performing artists. For example, TJQ is one of the training tools employed by Phillip Zarrilli (2009) in psychophysical acting for the purpose of attuning the performer's body and mind, enhancing their perceptual and sensory awareness, and experiencing the circulation and shaping of energy. The metaphysical philosophy contained in TJQ underlies my performance-making practice as a teacher, maker and performer. I view TJQ not only as a martial art form, but also as a performing art form, because it shares the same essential concepts as performing arts: space, time, energy. Therefore, I have applied the elements of TJQ and designed exercises to train contemporary theatre performers. The core of this unique movement training is based on the motion principle of TJQ, which is the consciousness guiding the $q i$, the $q i$ guiding the body, and then the body forming the shape. Practitioners are expected to improvise whilst being aware of qi, and therefore to be able to stimulate spontaneity in improvisation, as well as to achieve the moment of integration of the body and mind: doing and being.

Since 2014, I have delivered Tai Jibased movement workshops to Bachelor of Performing Arts students and Bachelor of Dance students at the Western Australian Academy of Performing Arts (WAAPA). In Psychophysical Acting, Zarrilli argues that transporting TJQ, Yoga and Kalarippayattu to contemporary acting involves a triple process, which is 'moving from a martial / meditation art to performance, from an Asian to a cosmopolitan context, and from teaching children to training adults' (2009, p. 82$)$. 
During the Tai Ji-based movement workshops, practitioners and I also navigated the shift from a martial arts / meditation context to that of performance and the application of Tai Ji in a cosmopolitan, rather than an exclusively Asian context. Our training began with an exploration of the essential principles of TJQ through simple exercises, which helped participants understand the idea of $q i$; become able to be aware of $q i$; and to move with qi. Their experiences of integrating the body and mind, and concentrating on the present moment were later applied to structured improvisations.

\section{Key Concepts of Tai Ji-Based Movement Training}

\section{Qi}

$Q i$ is the essential material enveloping and penetrating all that exists. In its concrete form, 'essence and material force (qi) are combined to become things' (Chan, 1963, p. 265). It is usually associated symbolically with natural elements like air, fog or clouds in Chinese ancient sources, and also refers to things which are perceivable but intangible, such as atmosphere and smoke. In modern physics, 'like the quantum field, Chi [qi] is conceived as a tenuous and nonperceptible form of matter which is present throughout space and can condense into solid material objects' (Capra, 1983, p. 213). In its subtle form, $q i$ is the essential life force of the human body that animates one's life activities both consciously and unconsciously, and is transferred from one part of the human body to another. In short, qi exists in various forms, from the smallest particle or element to the vast universe, from the visible motion of nature to the invisible activity of consciousness. Instead of saying that we feel qi, it is more accurate to say that we are qi or we manifest $q i$ all the time. According to 
Geoffrey Samuel and Jay Johnston, to conceptualise $q i$ in the body:

imagine a fluid-filled sack under water. The sack has a semipermeable membrane: it can absorb the external fluid and excrete fluid out. The water surrounding the sack has waves that also influence its inner fluids. (2013, p. 21)

Therefore, it can be seen that $q i$ is the flow of energy circulating in the human body; it functions in accordance with the relationship between the cosmos and human beings. When the qi that is present in a human being responds to the $q i$ in the universe, then the human is energetically connected with the universe at that moment, thus realising the pursuit of the unification of nature with humanity in Tai $\mathrm{Ji}$ philosophy. One workshop participant commented about qi that 'if you can feel, you got it, it's right there. [You] become very aware' (Focus group 1, 10 April 2014). Another participant reported that:

...the simplicity of Tai Ji also struck me, when you just feel the energy in your hands, doing nothing but standing still, there is very little happening. That's such a simple thing to do, but it's [also] complex and hard' (Focus group 1, 10 April 2014).

Through the consciousness and resonance of qi, practitioners become more aware of the present moment, the interpersonal communication in the specific space and the unity of the microcosm (a human being) with the macrocosm (the universe).

The body is considered the fundamental location of energetic transformation in $T J Q$, and the purpose of the practice is to be conscious of $q i$ that is present in one's body and then motivate continuous physical movement in order to maintain a smooth circulation of qi within the body. It should be noticed that although 'energy' is frequently used to describe and discuss $q i$ in qi-related practices, such as Qigong and TJQ, it would be too simplistic to equate $q i$ and energy. Qi can be considered as a form of energy when practitioners may be able to feel subtle streaming-like sensations go through the 
body as a consequence of the practice with sustained concentration. However, the perception of $q i$ is very different to the energy or force that is generated by intense physical and muscular effort, which is more likely to emphasise the capacity of weight bearing and explosive power during exercise. Therefore, to move whilst being aware of qi rather than with deliberate or muscular force is essential in TJQ practice. According to the legendary founder of $T J Q$, Zhang San-Feng:

the $q i$ should be active as the propellent power behind all movements and the spirit should be gathered internally, so that there will be no defects, nor any uneven distribution nor any discontinuation anywhere (as cited in, Yu, 1994, p.143).

The emphasis on continuity and flexibility encourage a description of the performance of $T J Q$ as 'water flowing down the river incessantly' (Yu,1994, p. 149). The flowing state of practice also distinguishes TJQ from other forms of martial arts.

\section{Body-mind}

Western ways of thinking were influenced by Descartes' fifteenth-century theories of what became known as Cartesian mindbody dualism. These theories were influential in establishing the predominant understanding that the mind is superior to the body in Western understandings of self and the world. The legacy of the mindbody split has manifested in many ways, including in the claim by De Guevara that 'it is extremely difficult to understand the primacy of the body in a human being's existence when the body often tends to largely disappear from one's awareness' (2014, p. 26). Likewise, there is a history of challenging this duality to question the effect of the hierarchical process of the mind-body split, including phenomenology, neuroscience, and cognitive science. As a result of extensive neuroscience research, Damasio proposes the concept of the 'living organism' as arising when 'the brain- 
body partnership intersects with the environment as an ensemble, the interaction being of neither the body nor the brain alone' (1996, p. 88).

Chinese thinking posits that the mind is interpreted through a cluster of meanings. For example, the mind is usually translated as 'hsin [心] - which can also mean "heart"; in fact, though, it fuses both concepts, and might be better translated as "heart-mind" or the "thinking heart"' (Cooper, 2003, p. 63). Similarly, according to Yuasa Yasuo (1993), the Chinese character xin [心] or kokoro in Japanese, could be translated as mind, which 'embraces the affective dimension of the heart' (p. 204). It is often assumed that the heart is the most vital organ that produces feelings and emotions. Chinese Confucian philosopher Xunzi (310 BC $235 \mathrm{BC}$ ) suggests that mind functions as a sense like the eye, the ear, the mouth and the nose, so that 'the feelings of pleasure, anger, sorrow, joy, like, dislike, and desire are distinctions made by the mind' (as cited in Chan, 1963, p.125). In this way, the mind not only refers to the emotion, but also implies desire and attention, which can be understood as a psychological dimension of a human being and is correlated with consciousness. Another Confucianist, Mencius (372 BC - 289 BC), discusses the power of mind and its interaction with qi: 'if the will [mental power] is concentrated, the vital force [will follow it] and become active. If the vital force is concentrated, the will [will follow it] and become active' (as cited in Chan, 1963, p. 63). The power of mindfulness is clearly highlighted in TJQ practice in that all movements are motivated by mindintention, and the mindful state is required throughout the entire practice process. G. Alan Marlatt \& Jean L. Kristeller describe mindfulness in the same way, which is 'bringing one's complete attention to the present experience on a moment-tomoment basis' (1999, p. 68). Thus, when 
the mind moves, the qi follows, and when the qi arrives, the body moves. The TJQ practice requires body-mind to interact with the surrounding environment as an ensemble, neither the body nor the mind alone. In addition, based on this concept of the interrelation of consciousness, emotion and attentiveness, this state of consciousness can be further embodied and transformed when engaging in Tai Jibased improvisation, that is consciousness guiding the qi, qi guiding the body, and body forming the shape.

\section{Wu-wei}

One of the most fundamental notions in Daoism is wu-wei (无为). Literally, wu-wei means 'non-action', but philosophically speaking it implies taking no 'unnatural action'. In Dao De Jing, wu-wei implies that 'By acting without action, all things will be in order' (as cited in, Chan, 196, p. 141). Alan Watts describes taking no action as: "not forcing". . . what we mean by going with the grain, rolling with the punch, swimming with the current, trimming sails to the wind, taking the tide at its flood, and stooping to conquer (1975, p. 76$)$.

In other words, the notion of wu-wei means that people do not take action that is opposite to nature, but rather let nature follow its own course. This notion of wuwei echoes the ultimate principle of 'dao' in Daoism, which is that 'Tao [dao] invariably takes no action, and yet there is nothing left undone' (as cited in Chan, 1963, p. 158). Daoist philosopher, Zhuangzi (369 BC - 286 BC) stresses the metaphysical and aesthetic aspects of wu-wei. In his view, wu-wei is not merely a means to achieve an ultimate aim but is transcendental, and becomes an end in itself. In this way, wu-wei is freedom: if one can eliminate rigid ways of thinking, then one has infinite possibilities to create and capture immediate delight. Wu-wei is also a pure aesthetic experience; it derives from intuition and acts with spontaneity and 
without excessive subjective judgment. Rui Zhu (2002) argues that there is a parallel between Kant's idea of beauty being purposiveness without purpose and the aesthetic nature of wu-wei for Zhuangzi. Zhu suggests that 'both the aesthetic judgement and wu-wei are activities of intuition . . . both wu-wei and the aesthetic judgement represent a state of mind in which the unity of the subjective and objective, man and the world, comes into being' (2002, p. 60-61).

The emphasis of not forcing in wuwei corresponds to the 'acceptance' that is one of the foundations of mindfulness practice. According to Hayes, acceptance suggests 'experienc[ing] events fully and without defense, as they are' (1994, p. 30).

Taking no action and following the nature favoured in wu-wei is comparable to the primary intention of spontaneity emphasised in improvisation. It is widely believed that in Western modern dance, improvisation is often used as a means or a process of generating new movement ideas and stimulating the potential of the body through unrehearsed and spontaneous motion. Compared to choreography, improvisation is considered to be 'a form which lives and breathes only in the momentary flow of its creation ... To dance the dance as it comes into being at this particular moment at this particular place' (Sheets-Johnstone, 1981, p. 400). However, the understanding of improvisation should not be limited to a specific form or culture. As Yu recalled of his talk with some American friends and scholars, 'I was shocked to hear them say that "there is no improvisation concept in Chinese thought"' (1994, p. 106). Actually, the notion of wu-wei and its pursuits have demonstrated the importance of spontaneity in Chinese art. In fact, one of the ultimate pursuits for artists is seen as casting off normative ways of thinking and committing oneself in action, holistically 
driven by flowing energy, in order to free oneself.

\section{Tai Ji-based Movement Training}

In Tai Ji-based movement workshops, I set up a series of exercises for participants to experience essential principles of TJQ, such as the integration of body and mind, the qi field, the flow of $q i$, and the notion that moving starts from the body centre. These exercises move in accordance with the principle of the consciousness guiding the $q i$, the qi guiding the body, then the body forming the shape. The purpose of this unique training is not to cultivate Chinese martial artists, but to allow participants to re-examine physical and mental states, and to understand their body and movements better in accordance with the requirement of contemporary theatre performance. The approaches developed in this research project can be effective supplements to existing psychophysical training, whether in dance or acting.

In the next section, I will take two exercises of the Tai Ji-based movement training as examples, analysing the function of each exercise, and sharing the reflections of participants about their experiences.

\section{Warm up}

Each workshop usually starts with a breathing exercise, which allows practitioners to perceive and cultivate qi. Standing with feet shoulder-width apart, and arms bent into an arc, hands are gently placed on the abdomen. Breathing deeply into the abdominal area with each inhalation, practitioners are encouraged to slightly exaggerate the expansion of the abdomen to help feel the experience of the qi flowing through the nostrils and down to the navel. With each exhalation, they are encouraged to slightly exaggerate the contraction of the abdomen, to help feel and experience the qi spreading through 
the whole body and penetrating into the fingertips and heels. Most importantly, practitioners make each breath as long and full as possible while still breathing comfortably. This warm-up generally lasts around 10 minutes and functions to prepare practitioners by cultivating psychophysical awareness.

\section{Exercise 1: Mapping}

Mapping is not an extract from TJQ moves but an exercise inspired by the understanding of energy channelmeridians in traditional Chinese medicine. Unlike organ-oriented medicine in the West,

[Chinese] acupuncture medicine takes each viscus to be functionally connected with other viscera through a physiologically invisible network of what is called "meridians". (Nagatomo, 2002, p.174)

Meridians are considered pathways in which the qi flows. If the circulation of $q i$ is blocked, health issues are likely to occur, and if the force becomes dominant in TJQ practice, it will block the circulation of blood and qi. That is, the continuous flow of $q i$ emphasised in TJQ will benefit the smooth circulation of meridians in the body and thus contribute to one's health. The reason for ignoring the energy channels and the motion of meridians is probably due to an excessive focus being placed on the muscles and external appearance of performers.

The aim of the mapping exercise is to awaken every muscle and to prepare the body to move by experiencing how the flow of energy runs through the body. Therefore, I incorporated the movement of finger lines on the body into an exercise called Mapping, which aims to improve the understanding of meridians, energy channels, and encourage psychophysical awareness through the visualisation of the flow of qi in body movements. In doing this exercise, a participant 'simultaneously senses the inner feeling of the 
kinaesthetic/verbal form in-action as it is performed' (Zarrilli, 2009, p. 20).

In this exercise, each participant (performer) stands with a partner - also called a drawer - who is trying to map the journey of meridians clearly with their fingers on the performer's body. The tracing resembles the movement of meridians in the body, using external stimulations from the partner, and is conducted as an improvisation. During the journey, a drawer is asked to move their fingers along the 'meridians' of the performer's body without any break or skipping, imagining there is water flowing within the body from one part to another, continuously. At the same time, performers experience the external stimulations and the immediate physical responses with the circulation of $q i$ in the body. The performer's movement stimulated from the encounter between the external surface of the body and the internal circulation of meridians can be seen not only as a contact improvisation, but also as an embodiment of the integrated body. That integrated body here implies the unity of the tangible or visible body structures (skin, joints and muscles) and the internal or invisible body operations (the circulation of $q i$ and meridians), which provide access to embodying psychophysical flow and integrated motion for performers. After mapping a journey on the performer's body for a few minutes, the drawers remove their fingers, but the performers maintain the kinaesthetic memory and move continually in response to that memory of sensation. In the flowing improvisation that follows, the performer's movement is stimulated by the circulation of $q i$ and the resulting impulses of the body, rather than responding to any external stimulus. Moreover, during the improvisation, I would ask the drawer to give stimulus to the performer's body when they think there is a need to motivate their partner's movement to help maintain the continuity of motion. 
In addition to being aware of the flow of energy, I also focus on another interpretation of flow during the process of improvisation, namely the 'autotelic experience' proposed by Mihaly Csikszentmihalyi (2015, p. 151). According to Csikszentmihalyi, flow is an autotelic experience:

a unified flowing from one moment to the next, in which he is in control of his actions, and in which there is little distinction between self and environment, between stimulus and response, or between past, present, and future. (2015, p. 151).

The word 'autotelic' implies that there are 'no external goals or external rewards . . . people seek flow primarily for itself, not for the incidental extrinsic rewards that may accrue from it' (2015, p.151). It should be noticed that the present-moment awareness that identifies the experience of flow also defines mindfulness. According to Susan Jackson, mindfulness and the flow state are highly interrelated, 'The flow state associated with high-level performance in any endeavour can be one outcome of being mindful in a challenging situation' (2016. p. 89).

Therefore, this psychological experience of flow corresponds both to the self-forgetfulness in wu-wei that can be gained during TJQ practice, and to the state-like phenomenon that is highlighted in mindfulness exercise, which is:

a kind of nonelaborative, nonjudgmental, present-centered awareness in which each thought, feeling, or sensation that arises in the attentional field is acknowledged and accepted as it is. (Bishop, et al. 2004, p. 232)

It can be seen that improvising with the flow of qi physically and consciously, as well as experiencing the autotelic flow at the moment of integration of body and mind, actor and action, would allow practitioners to achieve the momentary enlightenment and transcendence of $w u$ wei. 


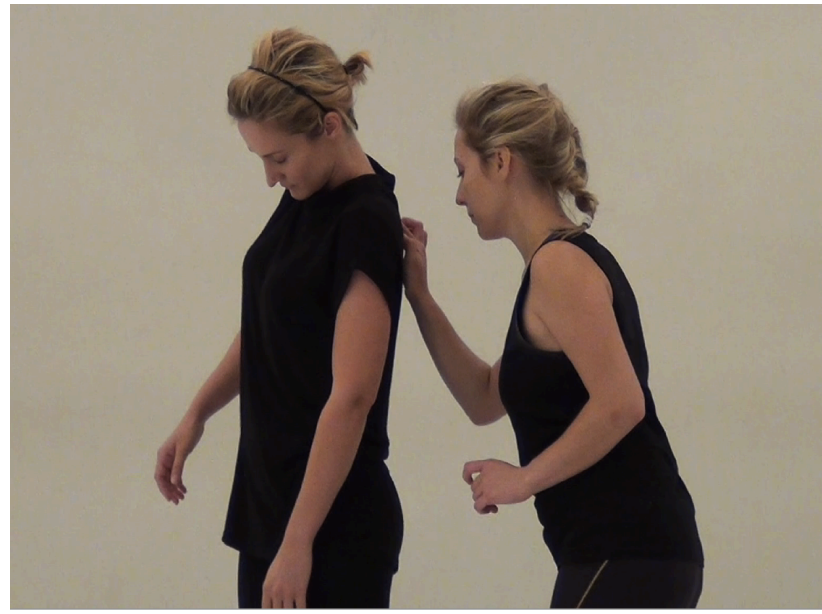

(Photo 1: Workshop participants (L-R): Kylie Bywaters and Julia Landberg. Photo taken by Min Zhu on 9 May 2016.)

According to workshop participants, this exercise allows them to become more aware of what is physically happening in the present moment. The enhanced body awareness not only expands their perceptions of the circulation of qi within the body, but also improves the articulation of the body during the motion. In the focus group discussion, one participant described the feeling she gained from the mapping exercise:

It really helps me with remembering that the whole body is connected. When I first started acting a long time ago, you would feel legs and top were not connected, you have to keep reminding yourself to move your feet ... So, it is really helpful for me to do things like this, everything is one and each movement affects everything else (Focus group 3, 2 August 2015).

\section{Exercise 2: Duet improvisation}

In this exercise, participants begin by practising the basic TJQ form, Pushing Hands, focusing on the shift of weight and physical contact with consciousness rather than deliberate force. In the next section of the exercise, participants have more flexibility in choosing which parts of the body will be in contact, and which method they will use to respond to each other. A meditative mentality and relaxed body are required in this duet improvisation, but the self-defence function of the Pushing Hands exercise is replaced by seeking mutual understanding and an attempt to expand the qi field for participants. Internalising the consciousness of $q i$ in the body and being aware of the sympathetic, (perhaps even empathic), resonance between oneself and 
a partner. This can gradually create rhythmic motion during the process. After practicing on the spot for a few moments, the participants separate slowly but still maintain the magnetic connection between them based on the principle of listening to each other.

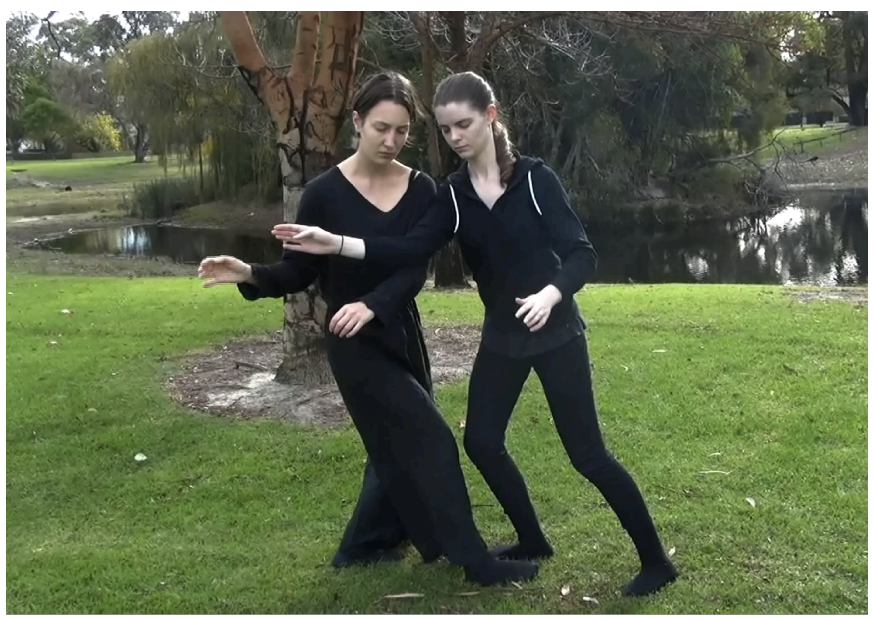

(Photo 2 Workshop participants (L-R): Indiana Coole, Rachael Woodward. Photo taken by Min Zhu on 9 May 2016.)

Regarding the conscious connection accomplished through the resonance of qi, one participant said:

At first, we were a bit sort of uncomfortable, and then as it went on we both committed to it and it became really profound, like, how I could connect to someone and understand them without really looking at them. And it really struck me how that could happen just because we were sharing something and both invested in it... it was [a] kind of mutual decision about what kind of relationship you'd have... who's leading this? It doesn't matter... If you applied that to Romeo and Juliet, the tension they have between the characters, it'd just become so much more interesting rather than two actors saying lines on stage, if they had the tension between them it would be, like, wow, I believe their energy. (Focus group 2, 7 March 2015)

The connection and interaction between a person and the surrounding people and the environment also corresponds to the definition of mindfulness, which is, 'the optimal interaction between attention and peripheral awareness' (Yates, 2015, p. 30). When performers bring their complete attention to the present experience, the enhanced sensory awareness will allow them to be more sensitive to the actions and reactions of others, which makes the transition from the context of meditation to performance possible, just as described by workshop participants. 


\section{Conclusion}

Whilst writing this article, I was asked to offer workshops to 3rd year Bachelor of Performing Arts students at WAAPA during the semi-lockdown placed on Perth. My workshops were expected to generate psychological and physical benefits to students, such as reducing stress and anxiety, enhancing awareness of the body, as well as achieving psychophysical relaxation and concentration.

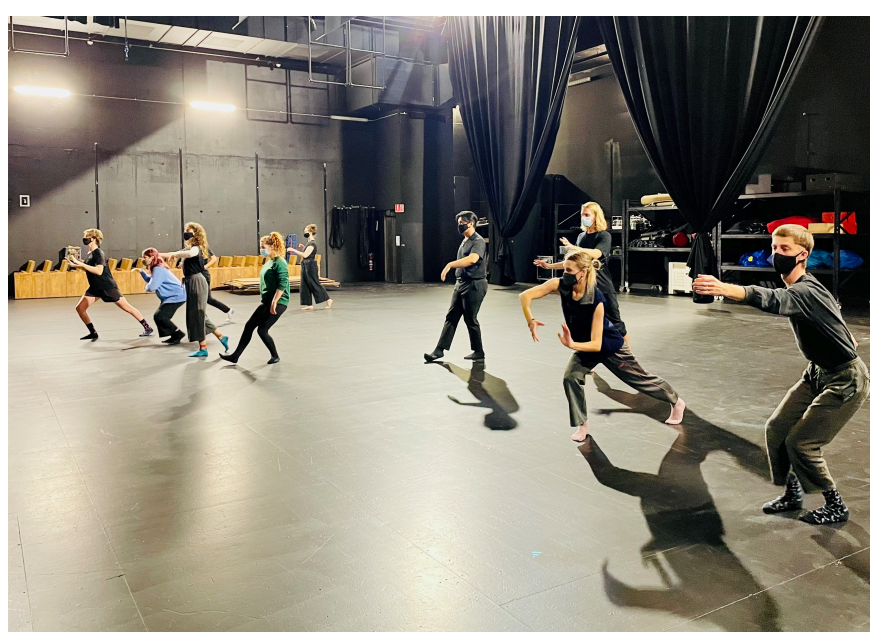

(Photo 3 Workshop participants: 3rd year Bachelor of Performing Arts students at WAAPA. Photo taken by Min Zhu on 3 May 2021.)

People have had to change their ways of living and working during the global pandemic, and mindfulness exercises have drawn great attention from the public as they 'can offer a helpful way to live with this constant change' (Behan, 2020, p.257). Tai Ji-based movement workshops provide theatre practitioners with a method to attend to movements and physical sensations, as well as to explore creativity in a relaxed and sustainable way even when wearing a mask.

The spontaneity can be embodied through the state of self-forgetfulness and also through becoming attuned to the breath of the surrounding environment. The experience of being aware of the $q i$ through the body with the least resistance, as well as moving with the great flow of energy without judgement, which practitioners gained from Tai Ji-based movement workshops allowed them to experience the moment of achieving the unity of body-mind in improvisation. TJQ is a mindfulness-based exercise, the Tai Ji- 
based movement training creatively applies a meditation / martial art practice to movement training for contemporary theatre performers. This application expects that the insights into the relationship between the body and the cosmos, and between the body and the mind underlined in TJQ, can motivate practitioners to explore alternative ways of moving, assisting in improving the learning of mindfulness skills, as well as broadening the possibilities of mindfulness practice.

\section{Notes}

1. In this article, I have used the Pinyin spelling (Chinese Phonetic Alphabet) for all Chinese words as opposed to the WadeGiles spelling; for example, Tai Ji Quan rather than Tai Chi Chuan.

\section{References}

Behan C (2020) "The benefits of meditation and mindfulness practices during times of crisis such as Covid-
19," Irish Journal of Psychological Medicine, 37(4), pp. 256-258.

doi: 10.1017/ipm.2020.38.

Bishop, S. R. et al. (2004) "Mindfulness: A proposed operational definition," Clinical Psychology: Science and Practice, 11(3), pp. 230-241. doi: 10.1093/clipsy.bph077.

Capra, F. (1983) The Tao of physics: An exploration of the parallels between modern physics and eastern mysticism. Rev. with afterword. London: Fontana (Flamingo).

Chan, W.-tsit (1963) A source book in Chinese philosophy. Princeton: Princeton University Press.

Cooper, D. E. (2003) World philosophies: an historical introduction. 2nd ed. Oxford, UK: Blackwell.

Csikszentmihalyi, M. (1990) Flow: The psychology of optimal experience. New York, NY: Harper and Row.

Csikszentmihalyi, M. (2015) A theoretical model for enjoyment. In A. Heble \& R. Caines (Eds.), The improvisation studies reader: Spontaneous acts .pp. 150-162. New York, NY: Routledge.

Damasio, A. R. (1996) Descartes error: emotion, reason and the human brain. London: Papermac.

De Guevara, V. R. (2011) Any body? The multiple bodies of the performer. In Pitches, J., \& Popat, S (Ed.), Performance perspectives: a critical introduction. Houndmills, England: Palgrave Macmillan.

Hayes, S. C. (1994). Content, context, and the types of psychological acceptance. In S. C. Hayes, N. S. Jacobson, V. M. Follette, \& M. J. Dougher (Eds.), 
Acceptance and change: Content and context in psychotherapy. pp. 13-32. Reno, NV: Context Press.

Huang, W.-S. (1984) Fundamentals of Tài Chi Chùan. Hong Kong: South Sky Book Co.

Jackson, S. (2016) Flow and Mindfulness in Performance in Baltzell, A. (ed.) Mindfulness and performance. New York, NY, USA: Cambridge University Press (Current Perspectives in Social and Behavioral Sciences).

Kabat-Zinn, J. (1994) Wherever you go, there you are: Mindfulness meditation in everyday life. New York: Hyperion.

Posadzki, P. and Jacques, S. (2009) "Tai Chi and Meditation," Journal of Holistic Nursing, 27(2), pp. 103-114.

Samuel, G. and Johnston, J. (2013) Religion and the subtle body in Asia and the west: Between mind and body. Hoboken: Taylor and Francis. Available at: http://public.ebookcentral. proquest.com/ch oice/publicfullrecord.aspx?p=1170337 (Accessed: May 27, 2021).

Sheets-Johnstone, M. (1981) "Thinking in Movement," The Journal of Aesthetics and Art Criticism, 39(4), pp. 399-407.

Marlatt, G. A., \& Kristeller, J. L. (1999) Mindfulness and meditation. In W. R. Miller Ed. Integrating spirituality into treat ment. pp. 67-84. Washington, DC: American Psychological Association.

Moyle, G. M. (2016) Mindfulness and dancers in Baltzell, A. (ed.) Mindfulness and Performance. New York, NY, USA: Cambridge University Press (Current
Perspectives in Social and Behavioral Sciences).

Nagatomo, S. (2002) "Ki-Energy: Invisible psychophysical energy," Asian Philosophy, 12(3), pp. 173-182.

Watts, A. (1975) Tao: The Watercourse Way. First ed. New York, USA: Pantheon.

Yasuo, Y. (1993) The body, self-cultivation, and Ki-energy. Albany: State University of New York Press.

Yates, J., 2015. The mind illuminated, Culadasa with Immergut and Graves, Hay House.

Yu, J.-W. (1995) The energy flow of the human being and the universe: Tai ji philosophy as an artistic and philosophical foundation for the development of Chinese contemporary dance. dissertation. Microform Publications, University of Oregon.

Zarrilli, P. B. (2008) Psychophysical acting: An intercultural approach after Stanislavski (rev. ed.). London: Routledge.

Zhu, R. (2002) "Wu-Wei: Lao-Zi, Zhuang-Zi and the aesthetic judgement," Asian Philosophy, 12(1), pp. 53-63. 